but is the only type found in Greenland ${ }^{4}$ and which is also common in southern Europe is probably completely isolated from the 38-and 46-chromosome types and should most likely be considered a separate species. It is undoubtedly split up in a number of subspecies ${ }^{4}$. The final decision as to the taxonomical status of the 38-chromosome 'palustris'-type and the 46-chromosome 'uniglumis'-type must await further morphological, cytological, and genetical investig. ations. The 10-chromosome type of Russian origin probably belongs to a different species. The plants of British origin with 92 and 69 chromosomes respectively which are referred to $H$. uniglumis ${ }^{6}$ have not been found in Scandinavia. They may represent natural tetraploids and triploids respectively of this species or they may belong to a separate species. There is a conspicuous difference in chromosome morphology between Heleocharis and Scirpus species (which is one argument against merging the two genera into one). Heleocharis species have rather long chromosomes whereas Scirpus species have very tiny ones. Several Scirpus species have very high chromosome numbers (100 or more) and it would be interesting to know the chromosome morphology of the British 92-chromosome $H$. uniglumis type which was counted by Hartshorne (unpublished, ref. 1).

This work was supported by a grant from the Carlsberg Foundation.

Lise H. Saunte

Institute of Genetics,

University of Copenhagen.

${ }^{2}$ Darlington, C. D., and Wylie, A. P., "Chromosome Atlas of Flowering Plants" (George Allen and Unwin, Ltd., London, 1955).

2 Walters, S. M., J. Ecol., 37, 192 (1949).

s Lôve, A., and Löve, D., "Chromosome Numbers of Narthern Plant Species" (Ingólfsprent, Reykjavik, 1948).

- Jørgensen, C. A., Sorrensen, Th., and Westergaard, M., Biol. Skr. Dan. Vid. Selsk., 9, No. 4, 3 (1958).

"Anderson, E., "Introgressive Hybridization" (John Wiley and Sons, Inc., New'York; Chapman and Hall, Ltd., London, 1919). Clapham, A. R. Tutin, T. G, and Warburg, E. F.; "Flora of the
British Isles"
(Cambridge University Press, 1952).

\section{Decision-making and the Communication of Information in an Industrial Setting}

THIs communication is concerned with structural or organizational variables which may affect the transmission of information. It deals with a study which was made of variations in the communication patterns of four light engineering factories carrying out the same work. The communication structures in these factories were considered from the point of view of the individuals whose work required them to make decisions or estimates from production information available to them.

'Decision' in this context refers to daily operational judgments which are similar and recurrent, the effectiveness of which appears particularly dependent upon a knowledge of the outcome of previous judgments made earlier in the series. The particular decision discussed here concerns the estimate of delivery - the length of time which it is judged will be taken to complete a customer's order. Accurate delivery was especially important in the four firms studied since they were supplying components to customers who were also manufacturers with delivery dates to fulfil.

The way in which delivery time was estimated differed in the four factories. In $W$ and $X$ it was carried out by works estimators on the shop floor who were also responsible for maintaining their estimates. In $Y$ and $Z$ estimating was the function of office staff, physically isolated from the works. Fulfilment of the estimate was here the responsibility of works personnel, themselves isolated from the estimating process.

In order to assess whether variations existed in the ability of the four estimators to judge accurately, estimated and actual delivery times were compared in each of the four firms for all orders received during the same period of four weeks. In making the comparison error was measured in terms of the number of days by which fulfilment of an order exceeded or fell short of the estimated time. The range of error for each firm and a condensed distribution of items within this range are given in Table 1.

Table 1

\begin{tabular}{|c|c|c|c|c|c|c|c|c|}
\hline & \multicolumn{2}{|c|}{ Estimates } & \multirow{2}{*}{ Range of error } & \multicolumn{5}{|c|}{$\begin{array}{l}\text { Percentage frequency of } \\
\text { error }(+ \text { and }-)\end{array}$} \\
\hline & No. & Range & & $\begin{array}{c}0-9 \\
\text { days }\end{array}$ & $\begin{array}{c}10-19 \\
\text { days }\end{array}$ & $\begin{array}{l}20-39 \\
\text { days }\end{array}$ & $\begin{array}{l}39+ \\
\text { dsys }\end{array}$ & \\
\hline $\begin{array}{l}W \\
X \\
Y \\
Z\end{array}$ & $\begin{array}{l}663 \\
338 \\
540 \\
461\end{array}$ & $\begin{array}{l}2-170 \\
2-185 \\
3-205 \\
3-256\end{array}$ & $\begin{array}{l}-214 \text { to }+78 \\
-197 \text { to }+74 \\
-187 \text { to }+149 \\
-198 \text { to }+115\end{array}$ & $\begin{array}{l}42 \\
26 \\
23 \\
19\end{array}$ & $\begin{array}{l}18 \\
24 \\
22 \\
15\end{array}$ & $\begin{array}{l}22 \\
29 \\
26 \\
30\end{array}$ & $\begin{array}{l}18 \\
21 \\
29 \\
36\end{array}$ & $\begin{array}{l}100 \\
100 \\
100 \\
100\end{array}$ \\
\hline
\end{tabular}

A more refined firm-by-firm comparison yielded the ranking $W, X, Y, Z$ in order of accuracy of delivery estimating.

It is not sufficient to attribute this greater accuracy in $W$ and $X$ to the fact that estimators in these firms were responsible for their estimates and so 'allowed themselves longer', since their performance was superior whether the error taken into account was that of over- or under-estimation. A more reasonable explanation may be put forward in informational terms. Their position in the communication structure appeared to allow to estimators in $W$ and $X$ a direct, continuous and fairly immediate knowledge of the outcome of their estimates. Direct knowledge of results was available through their daily association with the manufacturing side of the business. In the case of $Y$ and $Z$, any knowledge of results which existed appeared at best to be indirect, intermittent and retrospective.

This example illustrates one way in which the position of an estimator in a communication net may increase or reduce the likelihood of error in his estimates. It suggests that closer attention to structural variables and manipulation of the way in which a communication system is organized may help to reduce error commonly ascribed to unforseeable circumstances and uncontrollable factors.

The research to which this communication refers was sponsored by the Department of Scientific and Industrial Research and the Medical Research Council Joint Committee on Human Relations in Industry, and financed from Counterpart Funds derived from United States Economic Aid. A report has been submitted to the Committee. I am indebted to $\mathrm{Mr}$. J. W. Whitfield under whose direction the work was carried out.

\section{R. Sergean}

Medical Research Council

Industrial Psychology Research Group, Psychology Department, University College, London, W.C.1. Feb. 4. 